\title{
IMPLEMENTASI QR CODE BERBASIS ANDROID PADA SISTEM PRESENSI
}

\author{
Afif Priyambodo ${ }^{1}$, Koredianto Usman ${ }^{2}$, Ledya Novamizanti*3 \\ 1,2,3 Teknik Telekomunikasi, Universitas Telkom \\ Email: 1afifpriyambodo@gmail.com, ${ }^{2}$ korediantousman@telkomuniversity.ac.id, \\ ${ }^{3}$ ledyaldn@telkomuniversity.ac.id \\ *Penulis Korespondensi
}

(Naskah masuk: 10 Agustus 2019, diterima untuk diterbitkan: 07 Oktober 2020)

\begin{abstract}
Abstrak
Presensi merupakan hal utama dalam suatu kegiatan, karena menjadi bukti dari laporan pelaksanaan. Umumnya, presensi kehadiran dilakukan secara manual, yaitu siswa membubuhkan tanda tangan pada daftar hadir yang diedarkan, atau guru memanggil siswa satu persatu. Namun metode tersebut mengakibatkan terjadinya pemborosan waktu dan sumber daya. Hadirnya teknologi QR-Code berbasis android memberikan solusi agar presensi dapat berjalan dengan efisien. Penelitian ini memiliki tiga konfigurasi sistem, diantaranya sistem encoder, sistem hardware, dan sistem decoder. Sistem encoder melakukan proses encode data berupa Nomor Induk Siswa Nasional (NISN) menjadi QR-Code menggunakan kode Bose, Chaudhuri, Hocquenghem (BCH). Sistem hardware terdiri dari perangkat android dan kartu pelajar. Sistem decoder melakukan proses deteksi QR-Code dengan aplikasi Smart Presence. Sistem diuji dengan pengujian black box, pengujian jarak deteksi, pengujian deteksi berdasarkan cahaya, serta pengujian kartu pelajar bernoda dan rusak. Sistem presensi mampu mendeteksi QRCode dengan jarak minimal sebesar $3 \mathrm{~cm}$ dan jarak maksimal sebesar $45 \mathrm{~cm}$ dengan tingkat akurasi sebesar $98 \%$ dan rata-rata waktu komputasi sebesar 1,3 detik.
\end{abstract}

Kata Kunci: sistem presensi, android, QR-code, kode BCH

\section{IMPLEMENTATION OF ANDROID-BASED QR CODE IN THE PRESENCE SYSTEM}

\begin{abstract}
Presence is the main thing in an activity because it becomes evidence of the implementation report. Generally, attendance is done manually, i.e. students sign on the circulated attendance list, or the teacher calls students one by one. However, this method resulted in a waste of time and resources. The presence of Android-based QR-Code technology provides a solution so that the presence can run efficiently. This research has three system configurations, including the encoder system, hardware system, and decoder system. The encoder system encodes data in the form of a National Student Number (NISN) into a QR-Code using the Bose, Chaudhuri, Hocquenghem $(B C H)$ codes. The hardware system consists of an Android device and a student card. The decoder system carries out the QR-Code detection process with the Smart Presence application. The system was tested with black-box testing, detection distance testing, light-based detection testing, and stained and damaged student card testing. The presence system is able to detect QR-Code with a minimum distance of $3 \mathrm{~cm}$ and a maximum distance of 45 $\mathrm{cm}$ with an accuracy rate of $98 \%$ and an average computing time of 1.3 seconds.
\end{abstract}

Keywords: presence system, android, $Q R$-code, $B C H$ code.

\section{PENDAHULUAN}

Presensi digunakan sebagai bukti kehadiran dari suatu pelaksanaan kegiatan. Sistem presensi yang banyak diterapkan saat ini adalah presensi secara manual, yaitu siswa membubuhkan tanda tangan di kertas yang diedarkan, atau guru memanggil siswa satu persatu di awal pertemuan. Mengambil dan memeriksa kehadiran peserta oleh penyelenggara di setiap kegiatan adalah proses yang memakan waktu terutama ketika kelas besar. Hal tersebut juga menimbulkan pemborosan kertas dan kurang efisien.
Berbagai penerapan teknologi untuk sistem presensi sudah dilakukan, seperti penggunaan teknologi barcode, RFID, fingerprint, wajah, dan biometrik lainnya. Masalha dan Hirzallah mengusulkan sistem presensi yang menampilkan kode QR ke siswa selama atau di awal setiap kuliah. Para siswa perlu memindai kode untuk mengkonfirmasi kehadiran mereka (Masalha, Hirzallah, 2014). Soleh dan Muharom memanfaatkan smartphone untuk melakukan presensi ujian secara online. Nomor Ujian dan NIM mahasiswa ditampilkan menggunakan QR-Code yang telah 
tercetak di HP. Kemudian, pengawas ujian melakukan scanning QR-Code di HP mahasiswa secara satu persatu. Penelitian Norhikmah menggunakan QR Code untuk presensi pelatihan berbasis android. Waktu yang dibutuhkan yaitu 15 detik/idcard. Sedangkan presensi dengan membubuhkan tanda tangan di kertas membubuhkan waktu rata-rata $30 \mathrm{detik} /$ orang (Noerhikmah, dkk, 2016).

Makalah ini mengusulkan sistem presensi menggunakan Kode QR dengan smartphone berbasis android. Kode $Q R$ dibangkitkan dengan menggunakan program MATLAB, dan di cetak di kartu pelajar. Pengembangan berikutnya, kartu pelajar ini dapat digunakan untuk sistem parkir, transaksi di ATM, eToll, dan keperluan lainnya. Penggunaan kode Bose, Chaudhuri, Hocquenghem $(\mathrm{BCH})$ sebagai error correction menghasilkan sistem yang handal, karena dapat mengoreksi kesalahan ganda (multiple error correction). Dengan teknik ini, sistem tidak hanya akan menghemat waktu tetapi juga akan mempercepat proses rekapitulasi kehadiran, mengurangi penggunaan kertas, dan banyak waktu untuk pemaparan materi maupun aktifitas lainnya.

\section{METODE PENELITIAN}

\subsection{QUICK RESPONSE (QR) CODE}

$Q R$-Code adalah jenis simbol dua dimensi yang dikembangkan oleh Denso Wave pada tahun 1994. Setiap simbol $Q R$-Code disusun dalam bentuk persegi dan terdiri dari function patterns dan encoding region. Seluruh simbol dikelilingi oleh batas quiet zone pada keempat sisi. Terdapat 4 jenis pola fungsi meliputi finder pattern, separators, timing patterns, dan alignment patterns. Encoding region berisi data, yang mewakili informasi versi, format informasi, data dan koreksi kesalahan.

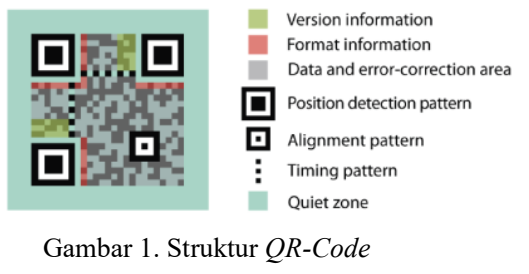

\subsection{KODE $B C H$}

Kode $B C H$ memiliki fungsi mengoreksi kesalahan ganda (multiple error corretion). Kode $\mathrm{BCH}$ membentuk kode siklik besar yang dapat mengoreksi kesalahan acak dengan kuat. Langkah awal kode $B C H$ adalah pembentukan kumpulan checkbit yang akan dikirimkan bersama informasi. Adapun proses pembentukan checkbit sebagai berikut:

1. Penentuan parameter $\mathrm{BCH}$ Code.

Parameter digunakan sebagai input dalam proses encode-decode $\mathrm{BCH}$ Code. Parameter tersebut meliputi :

$$
\begin{array}{ll}
\circ & \text { Variabel } m \\
\circ & \text { Panjang blok yang dikirim }: n=2^{m}-1
\end{array}
$$

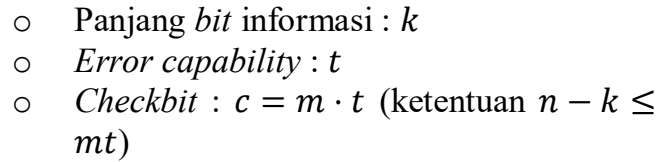

2. Bentuk Galois Field, GF $\left(2^{m}\right)$.

3. Menentukan minimal polynomial sebanyak $2 t-1$ buah.

4. Bentuk Generator polynomial $(g(x))$.

5. Bit informasi telah terbentuk, tambahkan bit 0 dibelakangnya sebanyak checkbit $(c)$.

6. Gabungkan bit biner dengan bit 0 dibagi dengan bit $g(x)$, diperoleh checkbit $(v(x))$.

7. Data informasi $(V(x))$ yang akan dikirim berupa bit informasi dan checkbit.

Decode $\mathrm{BCH}$ Code merupakan proses error detection dan error correction. Decode $\mathrm{BCH}$ Code mendeteksi error serta mengoreksi jika error ditemukan. Data bit yang didapatkan pada proses encode $\mathrm{BCH}$ code menjadi data input pada proses decode BCH Code. Adapun proses decode BCH Code sebagai berikut :

1. Data bit yang akan dikirim $(V(x))$ dibagi dengan generator polynomial $(g(x))$. Jika hasil pembagian $=0$, maka tidak ada error. Sebaliknya, jika hasil pembagian $=0$, berarti terdapat error dan harus melalui proses koreksi.

2. Menentukan nilai minimal polynomial $(2 t)$.

3. Menghitung syndrome dari codeword $\left(S_{1}, \ldots, S_{2 t}\right)$.

4. Membentuk Tabel BCH (algoritma PetersonBerlekamp).

5. Hasil dari Tabel $\mathrm{BCH}\left(\sigma^{(n)}(x)\right)$ adalah polinomial yang berfungi mendeteksi lokasi jika terdapat error.

6. Menentukan akar persamaan polinomial dengan metode trial dan error.

7. Menentukan nilai kebalikan dari akar persamaan polinomial. Nilai tersebut merupakan posisi dari bit error.

\subsection{ENCODING QR-CODE}

Proses Encode QR-Code merupakan proses mengubah data masukan menjadi simbol $Q R$-Code. Selain itu, proses encoding menentukan spesifikasi dari QR-Code. Pengkodean error correction dilakukan pada proses tersebut.
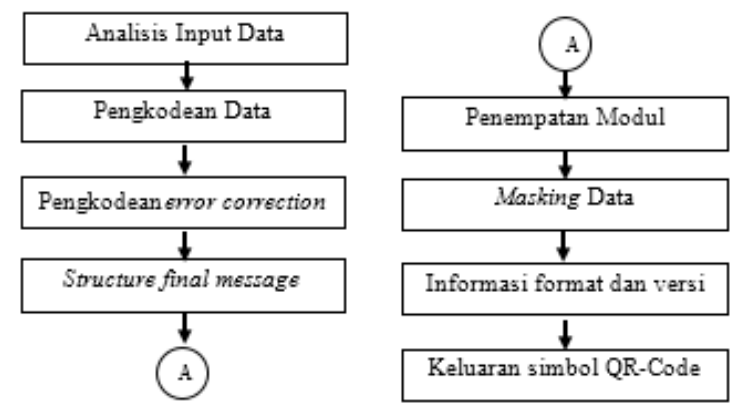

Gambar 2. Tahapan encoding $Q R$-Code 
Proses diawali dengan analisis input data. Selanjutnya data dikodekan menjadi bit. Pada proses encoding dilakukan konfigurasi spesifikasi $Q R$-Code berupa format dan versi. Tahapan pada proses encoding $Q R$-Code sebagai berikut:

1. Analisis data

QR-Code mengkodekan serangkaian teks dengan empat mode yaitu numeric, alphanumeric, byte, dan kanji. Setiap metode pengkodean dioptimalkan untuk mengkodekan data dengan sekumpulan bit sesingkat mungkin. Oleh karena itu analisis data digunakan untuk mengetahui apakah data yang dikodekan dalam mode numeric, alphanumeric, byte, atau kanji.

2. Pengkodean data

Data diubah menjadi serangkaian bit yang dipecah menjadi data codewords yang masingmasing memiliki 8 bit.

3. Pengkodean error correction

Pengkodean menghasilkan string bit data sebagai error correction codewords. Pemindai QR-Code membaca codewords data dan error correction codewords. Dengan membandingkan keduanya, pemindai dapat menentukan benar atau tidak dalam melakukan pemindaian. Jika pemindai tidak membaca dengan benar, maka dapat memperbaiki kesalahan.

4. Structure Final Message

Mengatur data dan error correction codewords yang dihasilkan. Data dan error correction disisipkan sesuai dengan spesifikasi $Q R$-Code.

5. Penempatan modul

Proses menempatkan bit pada matriks $Q R$ Code. Codewords disusun dalam matrik dengan cara tertentu.

6. Masking data

Mengubah pola modul sesuai spesifikasi $Q R$ Code. Spesifikasi mendefinisikan delapan mask pattern.

7. Informasi format dan versi

Format dan informasi versi ditambahkan ke dalam $Q R$-Code dengan menambahkan piksel pada area kode tertentu. Format piksel mengidentifikasi tingkat error correction dan mask pattern yang digunakan dalam $Q R$-Code.

\subsection{DECODING QR-CODE}

Decoding QR-Code merupakan proses mengubah simbol $Q R$-Code menjadi data informasi. Tahapan dalam melakukan proses decode QR-Code sebagai berikut:

1. Pengenalan modul

Mengenali modul gelap dan terang sebagai deretan bit " 0 " dan " 1 " dengan mencari dan mendapatkan gambar simbol.

2. Ekstrak format informasi

Decode format informasi, melepaskan pola masking dan menerapkan error correction.
3. Penentuan informasi versi

Menentukan versi simbol $Q R$-Code.

4. Melepas masking

MenXORkan decoding region bit dengan pola mask yang referensinya telah diekstras dari format informasi.

5. Mengembalikan data dan error correction Mengubah simbol menjadi bit data dan bit error correction codewords.

6. Error detection dan error correction Mengidentifikasi error dan memperbaiki dengan memanfaatkan error correction codewords.

7. Decode Data Codewords

Membagi data codewords menjadi beberapa segmen sesuai indikator mode dan indikator jumlah karakter. Decode karakter data sesuai mode yang digunakan dan output teks yang diterjemahkan sebagai hasilnya.
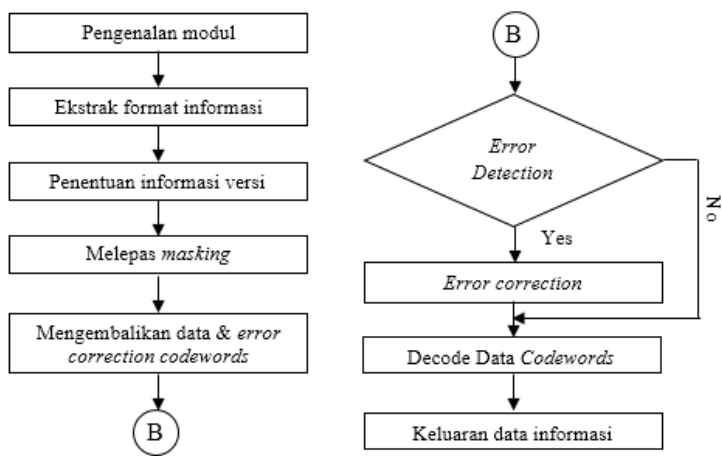

Gambar 3. Proses decoding QR-Code

\section{HASIL DAN PEMBAHASAN}

\subsection{SISTEM ENCODER}

Sistem encoder merupakan proses pengkodean data informasi menjadi QR-Code. Proses encode $Q R$ Code dilakukan dengan melibatkan kode $B C H$ sebagai error correction.

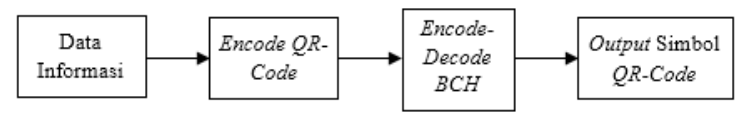

Gambar 4. Blok Diagram Sistem Encoder

Data informasi berupa Nomor Induk Siswa Nasional (NISN) menjadi input pada sistem encoder. Encode QR-Code merupakan proses pengkodean data menjadi simbol $Q R$-Code. Hasil dari proses encode menjadi inputan proses encode-decode $\mathrm{BCH}$ Code. Sistem encoder menghasilkan keluaran berupa simbol QR-Code.

\subsubsection{ENCODE QR-CODE}

Encode QR-Code mengkodekan data menjadi bit matriks. Sebelum itu, sistem mengkonfigurasi $Q R$ Code sesuai spesifikasi yang diinginkan. Gambar 5 menunjukan proses encode QR-Code. 


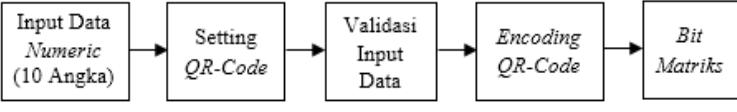

Gambar 5. Blok diagram encode QR-Code

Input data berupa text mode numeric berupa sepuluh angka (NISN). Kemudian, sistem melakukan konfigurasi QR-Code. Konfigurasi tersebut berpengaruh terhadap format QR-Code. Pada penelitian ini, paramater konfigurasi $Q R$-Code meliputi $\quad$ characterset $=U T F 8, \quad$ Versi $Q R-$ Code $=1$, initial size $=117$ dimana merupakan ukuran citra $Q R$-Code, quitezone size $=4$ yaitu menambahkan quite zone pada $Q R$-Code,size = $[$ initial size $+4 \cdot$ versi $Q R-$ Code, initial size + $4 \cdot$ versi $Q R-$ Code $]$ sehingga size $=[117+4$. $1,117+4 \cdot 1]$ atau [121 121] dimana merupakan ukuran $Q R$-Code. Selanjutnya, input data divalidasi untuk mengetahui mode input berupa numeric, alphanumeric, byte, atau kanji. Proses selanjutnya, input data dikodekan menjadi serangkaian bit yang dipecah menjadi codewords sesuai dengan konfigurasi QR-Code. Bit-bit tersebut dipetakan menjadi bit matriks dengan ukuran [121 121].

\subsubsection{ENCODE BCH CODE}

Setelah mendapatkan bit matriks, proses selanjutnya adalah error correction coding. Penelitian menggunakan $\mathrm{BCH}$ Code sebagai error correction code. Encode $B C H$ Code membentuk checkbit yang akan dikirim dengan bit matriks. Gambar 6 menunjukan proses encode BCH Code.

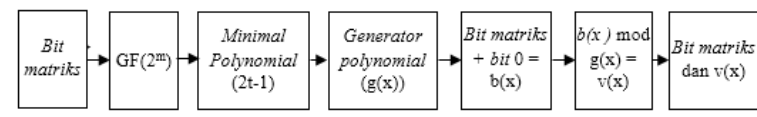

Gambar 6. Blok diagram encode BCH Code

Hal pertama yang dilakukan adalah membentuk Galois Field array $\left(2^{m}\right)$ dengan parameter yaitu $m=$ $9, n=2^{m}-1=511$ bit dimana $n$ adalah codeword length, $k=121$ dimana $k$ adalah panjang input, $t=$ 58 adalah kemampuan koreksi kesalahan, dan $c=$ $m \cdot t=522$ bit dimana $c$ adalah checkbit. Setelah melalui proses pembentukan $G F$, didapatkan nilai $m=9$ dan primpoly $=529$. Selanjutnya, menentukan minimal polynomial $(2 t-1)$. Untuk $t=$ 58 , terdapat 115 buah minimal polinomial, yaitu $\left(m_{1}(x), \ldots, m_{115}(x)\right)$. Kemudian membentuk generator polynomial $(g(x))$ dengan perhitungan $g(x)=K P K\left(m_{1}(x), \ldots, m_{115}(x)\right) . \quad$ Langkah selanjutnya, menentukan $b(x)$ dimana merupakan bit matriks ditambah bit 0 sebanyak 522 buah. Hitung nilai checkbit $(v(x))$ dengan rumus $b(x) \bmod g(x)$.

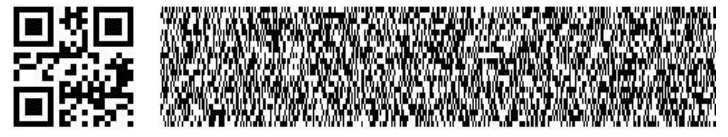

Gambar 7. Contoh bit matriks dan checkbit $(v(x))$
Bit matriks dan checkbit merupakan hasil proses encode BCH Code. Gambar 7 menunjukan bit matriks dan checkbit $(v(x))$. Hasil tersebut kemudian menjadi inputan pada proses decode $\mathrm{BCH}$ Code.

\subsubsection{DECODE BCH CODE}

Decode BCH Code merupakan proses deteksi error dan koreksi error. Bit matriks dan checkbit menjadi inputan pada proses ini. Bit matriks dan checkbit dicek terlebih dahulu agar diketahui apakah terdapat error atau tidak. Gambar 8 menunjukan diagram alir proses decode $\mathrm{BCH}$ Code.

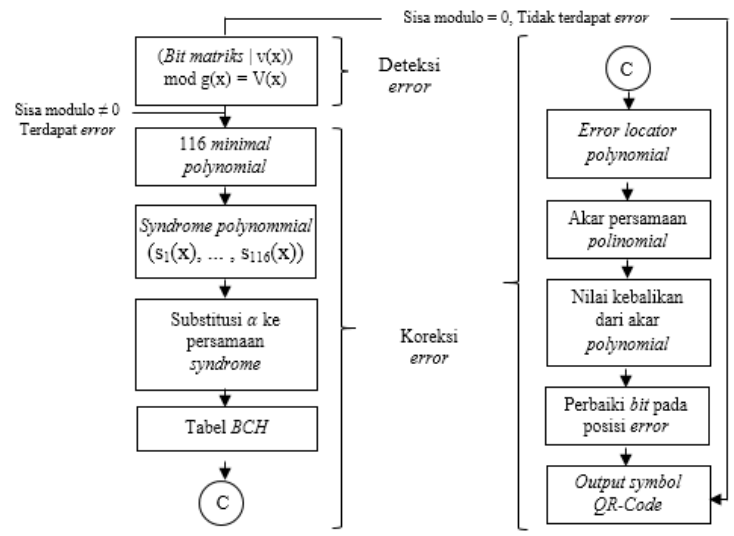

Gambar 8. Diagram alir decode BCH Code.

Proses pertama pada decode $\mathrm{BCH}$ Code adalah cek apakah terdapat error atau tidak. Pengecekan tersebut dilakukan dengan menghitung bit matriks | checkbit $(v(x)) \bmod g(x)$. Hasil mod dinamakan $V(x)$. Jika $V(x)=0$, maka tidak terdapat error dan bit matriks dikonversi menjadi barcode format $Q R$-Code. Jika $V(x) \neq 0$, maka terdapat error kemudian melanjutkan proses koreksi error.

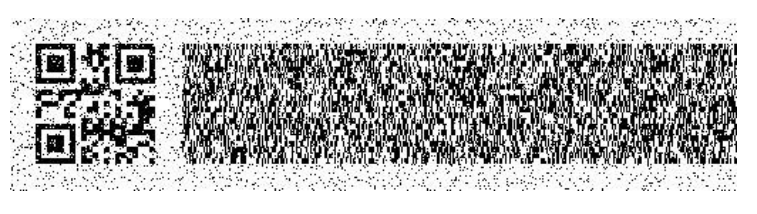

Gambar 9. Contoh sisa modulo $V(x) \neq 0$

Gambar 9 menunjukan nilai $V(x) \neq 0$, artinya bit matriks terdapat error. Langkah selanjutnya menghitung nilai minimal polynomial $(2 t)$ yang berjumlah 116. Kemudian hitung syndrome dari 116 minimal polynomial $\left(V(x) \bmod m_{1}(x), \ldots, V(x) \bmod m_{116}(x)\right)$

Selanjutnya, substitusi $\alpha$ ke persamaan tiap syndrome. Bentuk Tabel $B C H$ dengan algoritma Peterson-Berlekamp. Hasil dari tabel tersebut merupakan polinomial pendeteksi lokasi error $(\sigma(x))$. Cari akar dari polinomial pendeteksi lokasi error dengan mengganti nilai $\sigma(x)$. Persamaan polinomial lokasi error dengan field element pada GF $\left(2^{m}\right)$, $\left(\alpha^{k}\right)$, dengan ketentuan $0 \leq k \leq 511$, dan 
$\left.\sigma\left(\alpha^{k}\right)=0\right)$. Posisi bit error adalah nilai kebalikan dari akar yang diperoleh. Selanjutnya, perbaiki bit pada posisi yang error dengan membalikan nilai bit. Bit matriks berhasil diperbaiki dan dikonversi menjadi barcode format QR-Code. Gambar 10 menunjukan keluaran simbol $Q R$-Code yang merupakan hasil proses sistem encoder.

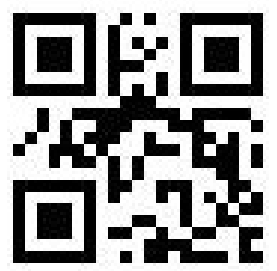

Gambar 10. Keluaran simbol QR-Code

\subsection{SISTEM HARDWARE}

Smartphone berbasis android digunakan sebagai alat scanning pada proses deteksi $Q R$-Code. Selain itu, penggunaan kartu pelajar dimana terletak $Q R$-Code itu sendiri berfungsi sebagai media dalam proses deteksi $Q R$-Code. Objek penelitian yaitu pada SMA Negeri 1 Kebumen. Desain kartu pelajar disesuaikan dengan format pada umumnya. Data siswa terletak pada bagian depan kartu pelajar. Simbol $Q R$-Code terletak pada bagian belakang kartu pelajar.

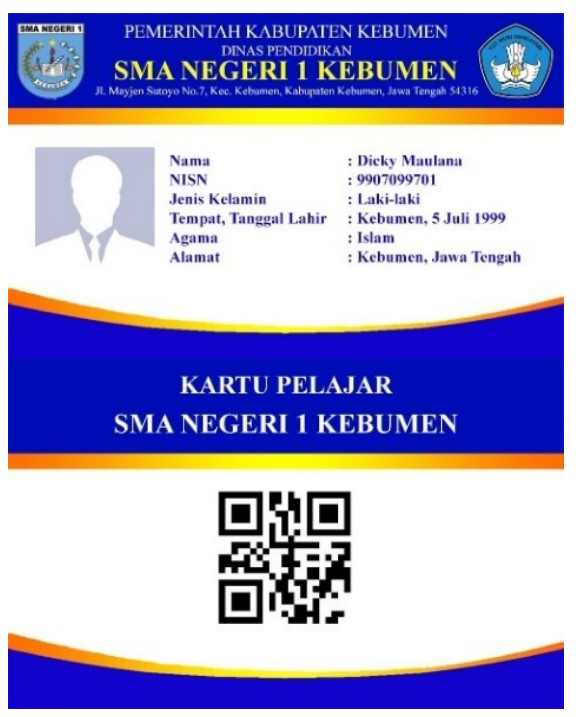

(b)

Gambar 11. Desain Kartu Pelajar (a) tampak depan, (b) tampak belakang.

\subsection{SISTEM DECODER}

Sistem decoder merupakan proses deteksi $Q R$ Code menjadi data informasi. Perangkat smartphone digunakan sebagai alat pendeteksi $Q R$-Code dengan aplikasi berbasis android. Aplikasi sistem presensi ini didesain menggunakan Android Studio sebagai aplikasi pendeteksi QR-Code. Selain itu, sistem decoder menggunakan kartu pelajar sebagai media dalam proses deteksi $Q R$-Code.

\subsubsection{DETEKSI $Q R$-CODE}

Deteksi $Q R$-Code mengubah $Q R$-Code menjadi data informasi. Secara garis besar, proses deteksi diawali dengan identifikasi QR-Code. Kemudian, sistem mengidentifikasi konfigurasi $Q R$-Code. Proses selanjutnya, sistem mendekode $Q R$-Code menjadi data informasi.

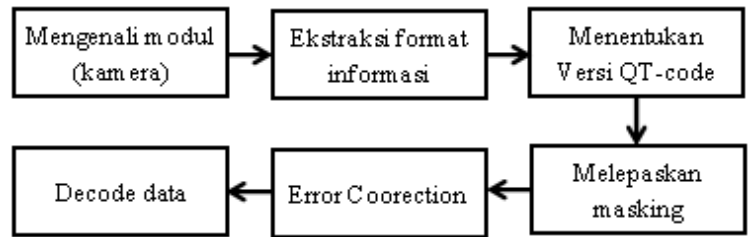

Gambar 12. Diagram alir deteksi $Q R$-Code

Kamera pada smartphone mengenali modul gelap dan terang sebagai deretan bit " 0 " dan " 1 " dengan cara scanning gambar $Q R$-Code. Selanjutnya, sistem mengidentifikasi konfigurasi QR-Code. Identifikasi $Q R$-Code mendapatkan versi $Q R$-Code dan format informasi. Format informasi diekstrak agar mendapatkan pola masking dan error correction. Sistem mengidentifikasi error dan memperbaiki jika terdapat error. Keluaran dari proses deteksi QR-Code berupa data informasi.

\subsubsection{APLIKASI BERBASIS ANDROID}

Aplikasi presensi berbasis android bernama Smart Presence melakukan proses deteksi $Q R$-Code menjadi data informasi.

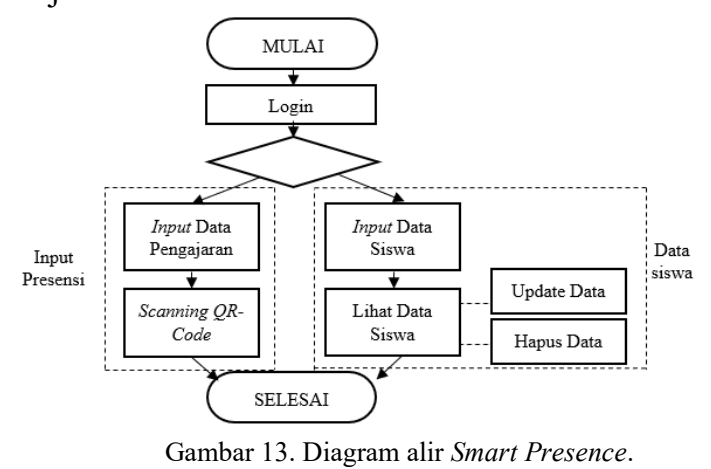

Pengajar melakukan proses login agar mendapatkan permission pada aplikasi Smart Presence. Setelah login, akan ada dua pilihan yaitu input presensi dan data siswa. Jika memilih input presensi, proses selanjutnya adalah mengisi data pengajaran meliputi nama pengajar, mata pelajaran, kelas, hari dan tanggal. Kemudian melakukan proses scanning QR-Code pada kartu pelajar agar mendapatkan data informasi dari $Q R$-Code. Jika memilih data siswa, maka akan muncul form database dimana berisi data siswa yang dapat membuat, melihat, menghapus dan merubah data. 


\subsubsection{DESAIN APLIKASI SMART PRESENCE}

Desain aplikasi Smart Presence dilakukan dengan program Android Studio. Aplikasi tersebut terintegrasi dengan Firebase database. Gambar 14 merupakan tampilan awal aplikasi.
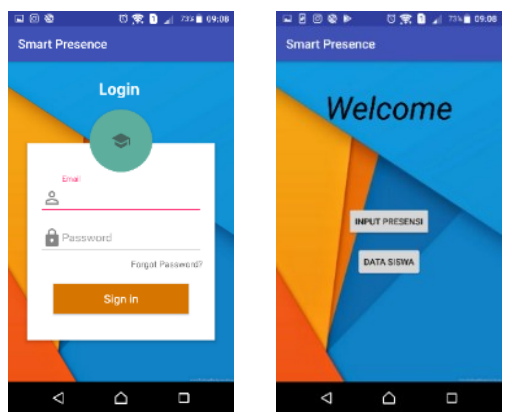

Gambar 14. Tampilan (a) login, (b) awal

Sistem terintegrasi dengan Firebase database yang berfungsi sebagai authentication dan database pada aplikasi Smart Presence. Admin akan mendaftarkan email dan password pada firebase. Pengajar melakukan login sesuai email dan password yang didapatkan.

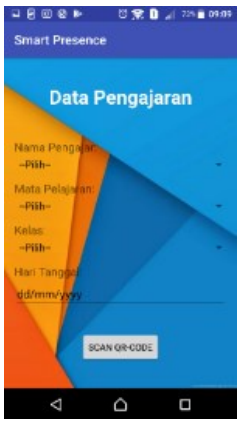

(a)

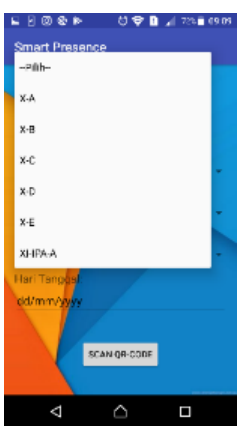

(d)

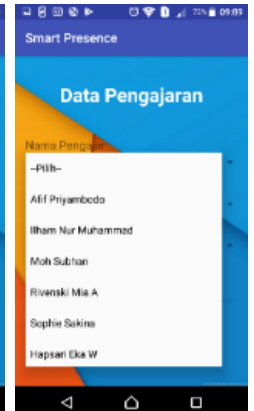

(b)

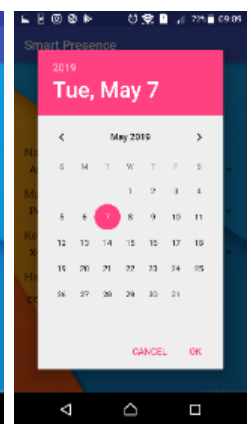

(e)

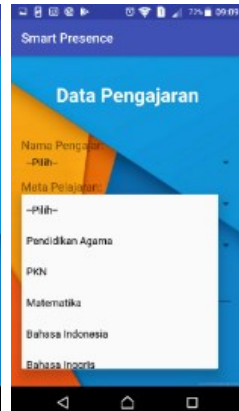

(c)

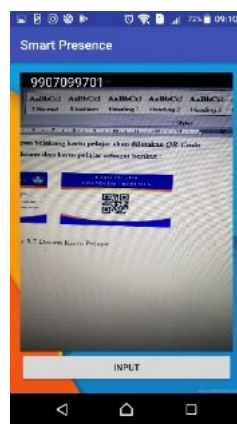

(f)
Gambar 15. Tampilan (a) Data pengajaran, (b) Nama pengajar, (c) Mata pelajaran, (d) Kelas, (e) Tanggal.

Tampilan awal terdiri dari dua pilihan yaitu input presensi dan data siswa. Input presensi dipilih jika akan melakukan proses penginputan siswa dalam presensi di kelas. Sedangkan data siswa dipilih jika akan menginput, melihat, mengupdate dan menghapus data siswa.

Tampilan data pengajaran berisi informasi mengenai nama pengajar, mata pelajaran, kelas dan tanggal pelaksanaan belajar-mengajar. Kartu pelajar di scan dan di decode menjadi data informasi berupa NISN. Data informasi ditampilkan pada layout ini. Aplikasi meminta user-permission untuk menggunakan kamera pada smartphone.

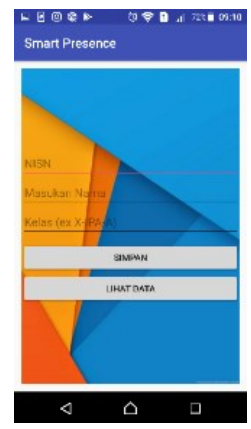

(a)

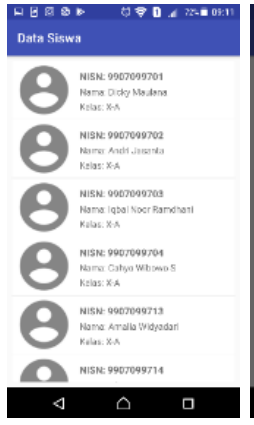

(b)

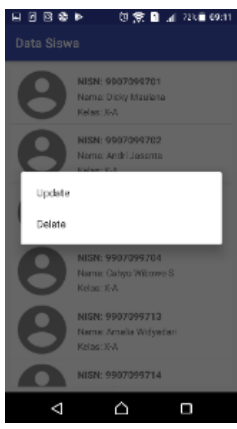

(c)
Gambar 16. Tampilan Database (a) Input data, (b) Lihat data, (c) Hapus data.

Tampilan database berisi perintah membuat, melihat, memperbaharui, dan menghapus data siswa. Aplikasi Smart Presence menggunakan firebase sebagai database dan authentication login. Setiap user memiliki database masing-masing.

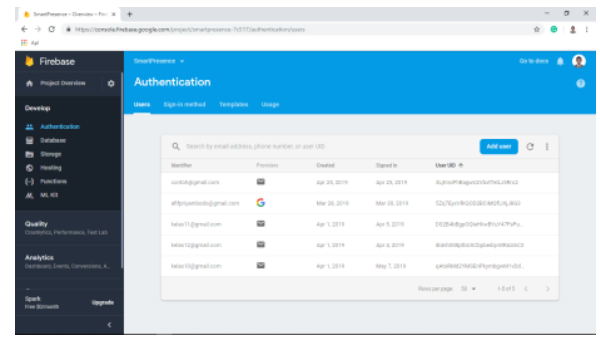

(a)

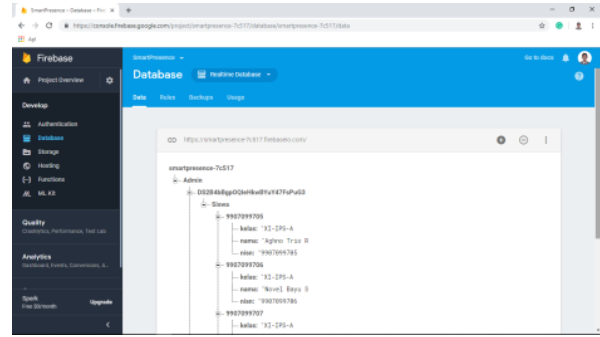

(b)

Gambar 17. Firebase (a) Authentication, (b) Database.

\subsubsection{IMPLEMENTASI SISTEM PRESENSI}

Penelitian ini mensimulasikan hasil dari konfigurasi sistem. Gambar 18 merupakan diagram alir dari sistem presensi di sekolah. Pengajar melakukan login pada aplikasi smart presence dengan mengisi email dan password. Admin memberikan email dan password kepada pengajar untuk melakukan authentication login pada aplikasi Smart Presence. Admin sudah terlebih dahulu mendaftarkan akun pada firebase authentication. Setelah pengajar mendapatkan permission login, pengajar melakukan input data pengajaran berupa 
nama pengajar, mata pelajaran, kelas, dan hari tanggal pengajaran. Kemudian pengajar melakukan scanning kartu pelajar (QR-Code) untuk mendapatkan NISN siswa. Hasil scanning akan dicocokan terhadap database siswa dan ditampilkan ke web sekolah sebagai data presensi.

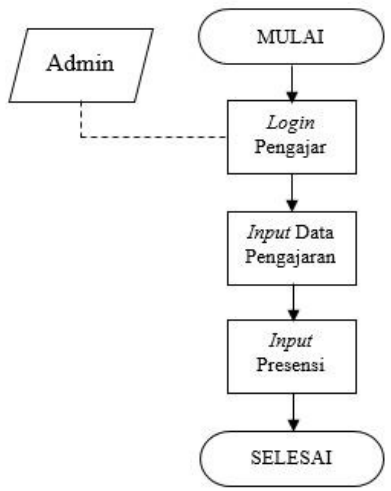

Gambar 18. Diagram alir sistem presensi sekolah.

\subsection{PENGUJIAN SISTEM}

Pengujian dilakukan untuk mengetahui performansi sistem. Skenario dirancang untuk melakukan beberapa pengujian terhadap aplikasi dan sistem presensi. Adapun parameter pengujian sebagai berikut :

1. Pengujian Black box, bertujuan untuk menguji fungsionalitas dari setiap tampilan pada aplikasi Smart Presence.

2. Pengujian jarak deteksi $Q R$-Code,bertujuan untuk mengetahui jarak minimum dan jarak maksimum pada proses deteksi QR-Code. Jarak yang digunakan pada pengujian adalah $1 \mathrm{~cm}$ sampai dengan diluar jangkauan deteksi QRCode. Pengujian dilakukan terhadap 10 kartu pelajar pada setiap jarak yang ditentukan.

3. Pengujian pengaruh cahaya dalam mendeteksi QR-Code, bertujuan untuk mengetahui keberhasilan deteksi QR-Code dalam berbagai intensitas cahaya. Sumber cahaya berasal dari kamera flash pada smartphone. Terdapat tiga kategori pengujian, yaitu intensitas cahaya yaitu ringan (1.856 lux), sedang (5.283 lux), dan berat (10.470 lux). Pengujian dilakukan terhadap 10 kartu pelajar pada setiap kategori.

4. Pengujian pengaruh noda dan rusak pada $Q R$ Code kartu, dimana kartu pelajar diberi noda dan dilakukan proses deteksi QR-Code. Terdapat tiga parameter pengujian yaitu, pengujian kotor tinta, pengujian kotor lumpur, dan pengujian gesekan atau goresan.

\subsection{HASIL PENGUJIAN SISTEM}

\subsubsection{PENGUJIAN BLACK BOX}

Pengujian black box dilakukan dengan fokus pada hasil keluaran yang diharapkan dari sistem yang diuji, apakah dapat berjalan sesuai yang diharapkan atau tidak. Tabel 1 merupakan hasil pengujian black box.

Tabel 1. Pengujian black box.

\begin{tabular}{|c|c|c|c|}
\hline No. & $\begin{array}{c}\text { Skenario } \\
\text { Pengujian }\end{array}$ & Hasil yang diharapkan & $\begin{array}{c}\text { Hasil } \\
\text { Pengujian }\end{array}$ \\
\hline 1 & $\begin{array}{l}\text { Autentifikasi } \\
\text { Password }\end{array}$ & $\begin{array}{l}\text { Jika data benar maka } \\
\text { tampilan menuju Layout } \\
\text { utama. } \\
\text { Jika data salah, maka } \\
\text { terdapat info "email } \\
\text { tidak valid"/ "wrong } \\
\text { password" di layar }\end{array}$ & Berhasil \\
\hline 2 & $\begin{array}{l}\text { Memilih tombol } \\
\text { Nama Pengajar, } \\
\text { Mata Pelajaran, } \\
\text { Kelas, dan } \\
\text { Jadwal Kelas }\end{array}$ & $\begin{array}{l}\text { Dapat menampilkan data } \\
\text { spinner Nama Pengajar, } \\
\text { Mata Pelajaran, Kelas, } \\
\text { dan Jadwal Kelas }\end{array}$ & Berhasil \\
\hline 3 & $\begin{array}{l}\text { Scanning } Q R- \\
\quad \text { Code }\end{array}$ & $\begin{array}{l}\text { Jika data benar maka } \\
\text { aplikasi melakukan } \\
\text { scanning } Q R \text {-Code dan } \\
\text { mendapatkan NISN. } \\
\text { Jika data salah maka } \\
\text { Text view menampilkan } \\
\text { info "No QR-Code } \\
\text { Detected" }\end{array}$ & Berhasil \\
\hline 4 & $\begin{array}{l}\text { Mengubah data } \\
\text { siswa }\end{array}$ & $\begin{array}{l}\text { Dapat mengupdate data } \\
\text { dan menampilkan info } \\
\text { "Data berhasil diubah" }\end{array}$ & Berhasil \\
\hline 5 & $\begin{array}{l}\text { Menghapus data } \\
\text { siswa }\end{array}$ & $\begin{array}{l}\text { Dapat menghapus data } \\
\text { siswa dan menampilkan } \\
\text { info "Data Berhasil } \\
\text { dihapus }\end{array}$ & Berhasil \\
\hline 6 & $\begin{array}{l}\text { Menampilkan } \\
\text { data siswa yang } \\
\text { tersimpan }\end{array}$ & $\begin{array}{l}\text { Dapat menampilkan data } \\
\text { siswa }\end{array}$ & Berhasil \\
\hline 7 & $\begin{array}{c}\text { Data yang } \\
\text { tersimpan masuk } \\
\text { ke dalam } \\
\text { database server }\end{array}$ & $\begin{array}{l}\text { Dapat terkoneksi ke } \\
\text { database server }\end{array}$ & Berhasil \\
\hline
\end{tabular}

\subsubsection{PENGUJIAN JARAK DETEKSI QR-CODE}

QR-Code dideteksi dengan aplikasi Smart Presence berdasarkan jarak yang ditentukan. Data yang diambil berupa waktu komputasi, jarak minimum dan jarak maksimum. Waktu komputasi dinilai berdasarkan waktu deteksi QR-Code menjadi data informasi. Tabel 2 merupakan hasil pengujian berdasarkan hjarak deteksi QR-Code.

\begin{tabular}{ccc}
\multicolumn{3}{c}{ Tabel 2. Pengujian jarak deteksi QR-Code. } \\
\hline $\begin{array}{c}\text { Jarak Deteksi } \\
\text { QR-Code }(\mathbf{c m})\end{array}$ & $\begin{array}{c}\text { Waktu Komputasi } \\
\text { (detik) }\end{array}$ & $\begin{array}{c}\text { Hasil } \\
\text { Pengujian }\end{array}$ \\
\hline 1 & - & Tidak berhasil \\
2 & - & Tidak berhasil \\
3 & 2.10 & Berhasil \\
4 & 2.04 & Berhasil \\
5 & 1.07 & Berhasil \\
10 & 0.85 & Berhasil \\
15 & 0.89 & Berhasil \\
20 & 1.07 & Berhasil \\
25 & 1.07 & Berhasil \\
30 & 1.12 & Berhasil \\
35 & 1.15 & Berhasil \\
40 & 1.20 & Berhasil \\
45 & 1.31 & Berhasil \\
50 & - & Tidak berhasil \\
Rata-rata & $\mathbf{1 . 2 6}$ & - \\
\hline
\end{tabular}

Berdasarkan Tabel 1, pengujian jarak deteksi $Q R$-Code memiliki jarak minimal sebesar $3 \mathrm{~cm}$ dan 
jarak maksimal $45 \mathrm{~cm}$. Pengujian menghasilkan waktu komputasi rata-rata sebesar 1,26 detik. Data hasil menunjukkan semakin jauh jarak deteksi semakin besar waktu komputasinya. Namun, pada jarak $10 \mathrm{~cm}$ hingga $1 \mathrm{~cm}$, waktu komputasi semakin besar. Hal tersebut didasari oleh berkurangnya fokus pada kamera smartphone dalam mendeteksi $Q R$ Code. Semakin dekat jarak deteksi, kamera semakin tidak fokus dalam mendeteksi $Q R$-Code.

\subsubsection{PENGUJIAN PENGARUH CAHAYA PADA DETEKSI QR-CODE}

Dilakukan variasi intensitas cahaya saat pengambilan gambar (scanning) QR-Code. Performansi sistem berupa tingkat akurasi dan waktu komputasi.

\begin{tabular}{ccc}
\multicolumn{2}{c}{ Tabel 3. Pengujian deteksi QR-Code berdasarkan cahaya. } \\
\hline Intensitas & $\begin{array}{c}\text { Akurasi } \\
\text { Cahaya }\end{array}$ & $\begin{array}{c}\text { Waktu Komputasi } \\
\text { (detik) }\end{array}$ \\
\hline Ringan & 100 & 0,89 \\
Sedang & 100 & 1,267 \\
Berat & 100 & 2,257 \\
Rata-rata & $\mathbf{1 0 0}$ & $\mathbf{1 , 4 7 1}$ \\
\hline
\end{tabular}

Berdasarkan Tabel 3, pengujian deteksi $Q R$ Code dengan gangguan cahaya memiliki akurasi $100 \%$ dan rata-rata waktu komputasi sebesar 1,471 detik. Waktu komputasi terkecil ada pada intensitas cahaya kategori ringan. Waktu komputasi terbesar ada pada intensitas cahaya kategori berat. Intensitas cahaya berpengaruh dalam proses deteksi $Q R$-Code. Semakin besar intensitas cahaya yang diberikan, semakin besar waktu komputasi deteksi.

\subsubsection{PENGUJIAN KOTOR TINTA}

Pengujian menggunakan tinta spidol dengan lima warna, yaitu merah, hitam, biru, hijau dan kuning. Terdapat tiga kategori rusak, yaitu ringan (3 goresan), sedang ( 5 goresan) dan berat (lebih dari 5 goresan). Setiap warna tinta, dilakukan pengujian terhadap sepuluh kartu pelajar di setiap kategori. Total pengujian sebanyak 150 kartu pelajar.

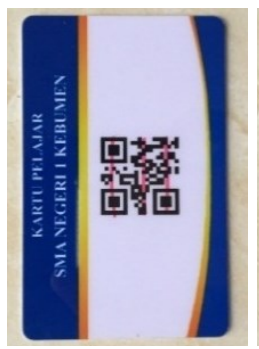

(a)

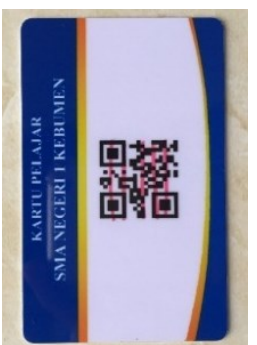

(b)

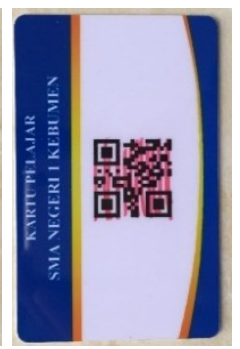

(c)
Gambar 19. Pengujian kotor tinta merah (a) Ringan, (b) Sedang, (c) Berat.

Berdasarkan Tabel 4, pengujian akibat kotor tinta memiliki akurasi 97\% dan rata-rata waktu komputasi sebesar 1,485 detik. Waktu komputasi terkecil, yakni 0,913 detik, pada kondisi tinta warna kuning tingkat ringan.

\begin{tabular}{cccc} 
Warna & \multicolumn{2}{c}{ Tabel 4. Pengujian kotor tinta. } \\
Tinta & Tingkat & $\begin{array}{c}\text { Akurasi } \\
\text { (\%) }\end{array}$ & $\begin{array}{c}\text { Waktu komputasi } \\
\text { (detik) }\end{array}$ \\
\hline \multirow{3}{*}{ Hitam } & Ringan & 100 & 1,527 \\
& Sedang & 100 & 2,174 \\
& Berat & 70 & 2,755 \\
Merah & Ringan & 100 & 1,017 \\
& Sedang & 100 & 1,065 \\
& Berat & 100 & 1,137 \\
Biru & Ringan & 100 & 1,524 \\
& Sedang & 100 & 2,082 \\
& Berat & 90 & 2,615 \\
& Ringan & 100 & 1,124 \\
& Sedang & 100 & 1,171 \\
& Berat & 100 & 1,327 \\
& Ringan & 100 & 0,913 \\
Kuning & Sedang & 100 & 0,916 \\
& Berat & 100 & 0,934 \\
\multicolumn{2}{c}{ Rata-rata } & $\mathbf{9 7}$ & $\mathbf{1 , 4 8 5}$ \\
\hline
\end{tabular}

Sedangkan rata-rata waktu komputasi terbesar, yakni 2,755 detik, pada kondisi tinta warna hitam tingkat berat. Warna tinta berpengaruh terhadap hasil waktu komputasi dan tingkat akurasi. Semakin gelap warna tinta semakin besar waktu komputasinya. Tinta warna hitam menghasilkan data waktu komputasi terbesar (tingkat ringan, sedang, dan berat) dibanding dengan warna lain. Kemudian tinta warna biru menghasilkan data terbesar kedua, dilanjut dengan tinta warna hijau, merah, dan kuning. Tingkat akurasi terendah, yakni $70 \%$ terjadi pada pengujian tinta hitam tingkat berat. Hal ini disebabkan tinta hitam membuat pola warna gambar pada $Q R$-Code menjadi berubah dan timpang tindih yang menyebabkan kesalahan pada proses scanning $Q R$-Code.

\subsubsection{PENGUJIAN KOTOR LUMPUR}

Pengujian dilakukan dengan cara menambahkan lumpur ke kartu pelajar (QR-Code) kemudian diratakan. Terdapat 3 kategori noda, yaitu ringan ( 1 tetes), sedang ( 2 tetes) dan berat (3 tetes). Pengujian dilakukan terhadap 10 kartu pelajar di setiap kategori. Total pengujian sebanyak 30 kartu pelajar.

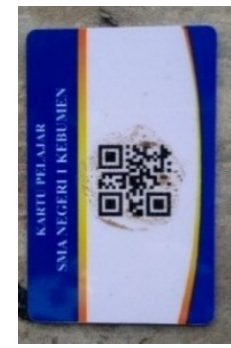

(a)

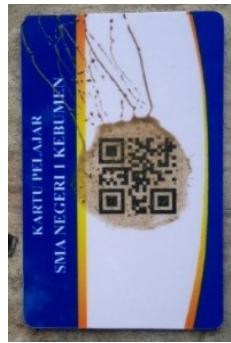

(b)

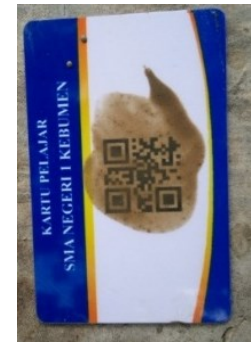

(c)
Gambar 20. Pengujian kotor lumpur (a) Ringan, (b) Sedang, (c) Berat. 
Tabel 5. Pengujian kotor lumpur.

\begin{tabular}{ccc}
\hline Takaran & $\begin{array}{c}\text { Akurasi } \\
\text { Lumpur }\end{array}$ & Waktu Komputasi (detik) \\
\hline Ringan & 100 & 0,89 \\
Sedang & 100 & 1,137 \\
Berat & 100 & 2,164 \\
Rata-rata & $\mathbf{1 0 0}$ & $\mathbf{1 , 3 9 7}$ \\
\hline
\end{tabular}

Berdasarkan Tabel 5, pengujian akibat kotor lumpur memiliki akurasi rata-rata sebesar $100 \%$ dan rata-rata waktu komputasi sebesar 1,397 detik. Waktu komputasi terkecil, yakni 0,89 detik. Waktu tesebut didapat pada kondisi tingkat takaran lumpur ringan. Sedangkan waktu komputasi terbesar, yakni 2,164 detik. Waktu didapat pada kondisi lumpur tingkat berat. Pengujian kotor lumpur memiliki pengaruh kecil terhadap waktu komputasi dan tingkat akurasi. Hal ini didasari dengan perbedaan data waktu yang sedikit dengan tingkat akurasi $100 \%$.

\subsubsection{PENGUJIAN GESEKAN/ GORESAN}

Pengujian dilakukan dengan cara menggesekan kartu pelajar (QR-Code) terhadap benda lain. Terdapat 3 kategori rusak, yaitu ringan (50 gesekan), sedang (100 gesekan) dan berat (150 gesekan). Pengujian dilakukan pada 10 kartu pelajar di setiap kategori. Total pengujian sebanyak 30 kartu pelajar.

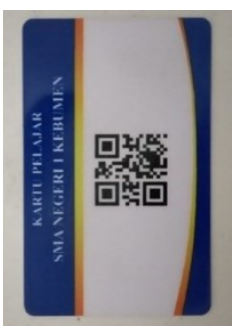

(a)

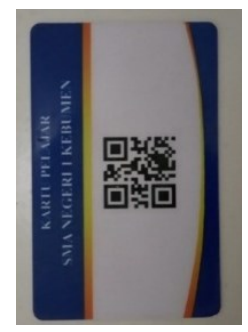

(b)

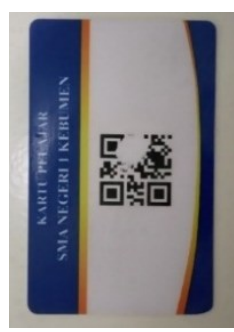

(c)
Gambar 21. Pengujian gesekan atau goresan (a) Ringan, (b) Sedang, (c) Berat.

Tabel 6. Pengujian gesekan atau goresan.

\begin{tabular}{ccc}
\hline $\begin{array}{c}\text { Tingkat } \\
\text { Goresan }\end{array}$ & Akurasi (\%) & $\begin{array}{c}\text { Waktu Komputasi } \\
\text { (detik) }\end{array}$ \\
\hline Ringan & 100 & 0,86 \\
Sedang & 100 & 0,88 \\
Berat & 90 & 0,92 \\
Rata-rata & $\mathbf{9 6}$ & $\mathbf{0 , 8 8}$ \\
\hline
\end{tabular}

Berdasarkan Tabel 6, pengujian akibat gesekan atau goresan memiliki akurasi sebesar $96 \%$ dan waktu komputasi sebesar 0,88 detik. Waktu komputasi terkecil, yakni 0,86 detik pada kondisi tingkat gesekan atau goresan ringan. Sedangkan waktu komputasi terbesar, yakni 0.91 detik pada kondisi tingkat gesekan atau goresan berat. Tingkat gesekan atau goresan berpengaruh terhadap hasil waktu komputasi pengujian. Semakin tinggi tingkat gesekan atau goresan semakin besar waktu komputasinya. Tingkat akurasi terendah, yakni $90 \%$ terjadi saat pengujian dengan tingkat gesekan atau goresan berat. Hal ini disebabkan gesekan atau goresan membuat pola gambar pada $Q R$-Code menjadi berubah atau hilang yang menyebabkan kesalahan pada proses scanning QR-Code.

\subsubsection{ANALISIS PERFORMANSI SISTEM}

Skenario pengujian dilakukan untuk menghitung rata-rata akurasi dan rata-rata waktu komputasi, dari hasil pengujian cahaya, kotor tinta, kotor lumpur, dan gesekan atau goresan.

\begin{tabular}{ccc}
\multicolumn{3}{c}{ Tabel 7. Performansi sistem. } \\
\hline Parameter & $\begin{array}{c}\text { Akurasi } \\
(\%)\end{array}$ & $\begin{array}{c}\text { Waktu Komputasi } \\
\text { (detik) }\end{array}$ \\
Pengujian & 100 & 1,471 \\
Cahaya & 97 & 1,485 \\
Kotor Tinta & 100 & 1,397 \\
Kotor Lumpur & 96 & 0,88 \\
Gesekan & $\mathbf{9 8}$ & $\mathbf{1 , 3}$ \\
Rata-rata & & \\
\hline
\end{tabular}

Berdasarkan Tabel 7, sistem memiliki akurasi $100 \%$ pada pengujian berdasarkan cahaya. $97 \%$ pada pengujian kotor tinta, $100 \%$ pada pengujian kotor lumpur, dan $96 \%$ pada pengujian gesekan atau goresan. Rata-rata waktu komputasi cahaya sebesar 1,471 detik, kotor tinta sebesar 1,485 detik, kotor lumpur sebesar 1,397 detik, dan gesekan atau goresan sebesar 0,88 detik.

Berdasarkan hasil seluruh pengujian, sistem memiliki tingkat akurasi $98 \%$, dan rata-rata waktu komputasi sebesar 1,3 detik. Tingkat akurasi dan waktu komputasi mengindikasikan sistem bekerja dengan baik.

\section{KESIMPULAN}

Penelitian ini telah melakukan desain dan implementasi $Q R$-Code berbasis android dengan kode Bose, Chaudhuri, Hocquenghem $(B C H)$ sebagai error correction untuk sistem presensi. Deteksi $Q R$ Code memiliki jarak minimal sebesar $3 \mathrm{~cm}$ dan jarak maksimal sebesar $45 \mathrm{~cm}$ dengan rata-rata waktu komputasi sebesar 1,26 detik. Secara keseluruhan, sistem yang dibuat pada penelitian ini memiliki akurasi sebesar $98 \%$ dan rata-rata waktu komputasi sebesar 1,3 detik.

Sistem dapat mengatasi gangguan cahaya pada kartu pelajar dengan akurasi $100 \%$. Semakin besar intensitas cahaya yang diberikan, semakin besar waktu komputasi deteksi. Sistem dapat mengatasi kerusakan kartu pelajar akibat kotor tinta berwarna hitam, merah, biru, hijau dan kuning pada kondisi ringan, sedang dan berat dengan akurasi $97 \%$. Semakin banyak dan gelap warna tinta yang diberikan, semakin besar waktu komputasi deteksi dikarenakan pola warna gambar pada $Q R$-Code berubah dan timpang tindih. Sistem dapat mengatasi kerusakan kartu pelajar akibat kotor lumpur. Pengujian kotor lumpur memiliki akurasi $100 \%$. Kotor lumpur tidak berpengaruh besar terhadap kerusakan kartu pelajar. Pada pengujian gesekan atau goresan, sistem memiliki akurasi $96 \%$. Gesekan atau goresan membuat pola gambar QR-Code menjadi berubah atau hilang. 


\section{DAFTAR PUSTAKA}

ASARE, I.T., 2015. The Effective Use of Quick Response (QR) Code as a Marketing Tool. IJESS, vol. 2, no. 12.

DE LIMA, N.V., NOVAMIZANTI, L., SUSATIO, E., 2019. Sistem Pengenalan Wajah 3D Menggunakan Icp Dan Svm. Jurnal Teknologi Informasi dan Ilmu Komputer (JTIIK), Vol. 6, No. 6, Desember 2019, hlm. 601-610.

M. LUKMAN, LUTFI A M. 2016. Smart Presence menggunakan QR-Code dengan enkripsi Vignere Cipher. Jember: Universitas Muhammadiyah Jember.

EKO, F S. 2014. Simulasi Kode Hamming, Kode $\mathrm{BCH}$, dan Kode Reed-Solomon untuk Optimalisasi Forward Error Correction. Makalah. Surakarta: Universitas Muhammadiyah Surakarta.

EKO, S. 2009. Analisis Kinerja Kode BCH. Medan: Universitas Sumatera Utara.

HERMANTO, N., NURFAIZAH, BAIHAQI, W. M., SARMINI., 2018. Implementation of QR Code and Imei on Android and Web-Based Student Presence Systems. 3rd International Conference on Information Technology, Information System and Electrical Engineering (ICITISEE). 13-14 Nov. 2018, Yogyakarta, Indonesia.

USMAN, K., SEPTIRASYAHYANI, NOVAMIZANTI, L., 2011. Desain dan Implementasi QR-Code Berbasiskan Pengolahan Citra untuk Sistem Parkir di IT Telkom. Bandung: IT Telkom.

INDARTONO, K., JAHIR, A., 2019. Prototype Sistem Keamanan Mobil Dengan Mengunakan Quick Response Code Berbasis Android dan Arduino. Jurnal Teknologi Informasi dan Ilmu Komputer (JTIIK), Vol. 6, No. 3, Juni 2019, hlm. 235-244.

MASALHA, F., HIRZALLAH, N., 2014. A Students Attendance System Using QR Code. International Journal of Advanced Computer Science and Applications (IJACSA), Vol. 5, No. 3, pp. 75-79.

NORHIKMAH, SAFITRI, A. R., SHOLIKHAN, L.A., 2016. Penggunaan QR Code dalam Presensi Berbasis Android. Seminar Nasional Teknologi Informasi dan Multimedia, pp. 97102. STMIK AMIKOM Yogyakarta, 6-7 Februari 2016.

KRISMANTO, P., USMAN, K., NOVAMIZANTI, L., 2011. Desain dan Implementasi Prototype Sistem Presensi Otomatis Berbasis Barcode Menggunakan Webcam dan Pengolahan Citra Digital di IT Telkom. Bandung: IT Telkom.

SHOLEH, M.L., MUHAROM, L.A., 2016. Smart Presensi Menggunakan QR Code dengan Enkripsi Vigenere Cipher. Limits, vol. 13, no. 2, Nopember 2016, pp. 31-44.
TIWARI, S., 2016. An Introduction to QR Code Technology. India: SITS Educators Society. 